\title{
Development of a diatom-based multimetric index for acid mine drainage impacted depressional wetlands
}

\author{
Luisa Riato $^{\mathrm{a}, *}$, Manel Leira ${ }^{\mathrm{b}, \mathrm{c}}$, Valentina Della Bella ${ }^{\mathrm{d}}$, Paul J. Oberholster ${ }^{\mathrm{a}, \mathrm{e}}$ \\ ${ }^{a}$ Department of Paraclinical Sciences, Faculty of Veterinary Science, University of Pretoria, \\ Private Bag X04, Onderstepoort, 0110, South Africa \\ ${ }^{b}$ Laboratório associado IDL, Faculdade de Ciências, Universidade de Lisboa, Campo Grande, Lisbon, 1749- \\ 016, Portugal \\ ${ }^{c}$ Department of Botany, Biology Faculty, University of Santiago de Compostela, Campus Sur, Santiago de \\ Compostela, 15076, Spain \\ ${ }^{d}$ Environmental Protection Agency of Umbria Region, ARPA UMBRIA, Via C. A. Dalla Chiesa 32, Terni, \\ 05100, Italy
}

${ }^{e}$ CSIR Natural Resources and the Environment, P.O. Box 320, Stellenbosch, 7599, South Africa

*Corresponding author. Tel: +27 764765245

Fax: +27 123492993

E-mail address: luisariato@gmail.com (L. Riato)

\section{Highllights}

- Diatom metrics are responsive to AMD pollution in depressional wetlands.

- Site classification by diatom typologies increases MMI performance.

- Simple metrics can be used beyond traditional species-based diatom assessment tools.

- This study highlights the discriminatory power of diatom-based metrics in wetlands. 


\section{Graphical abstract}

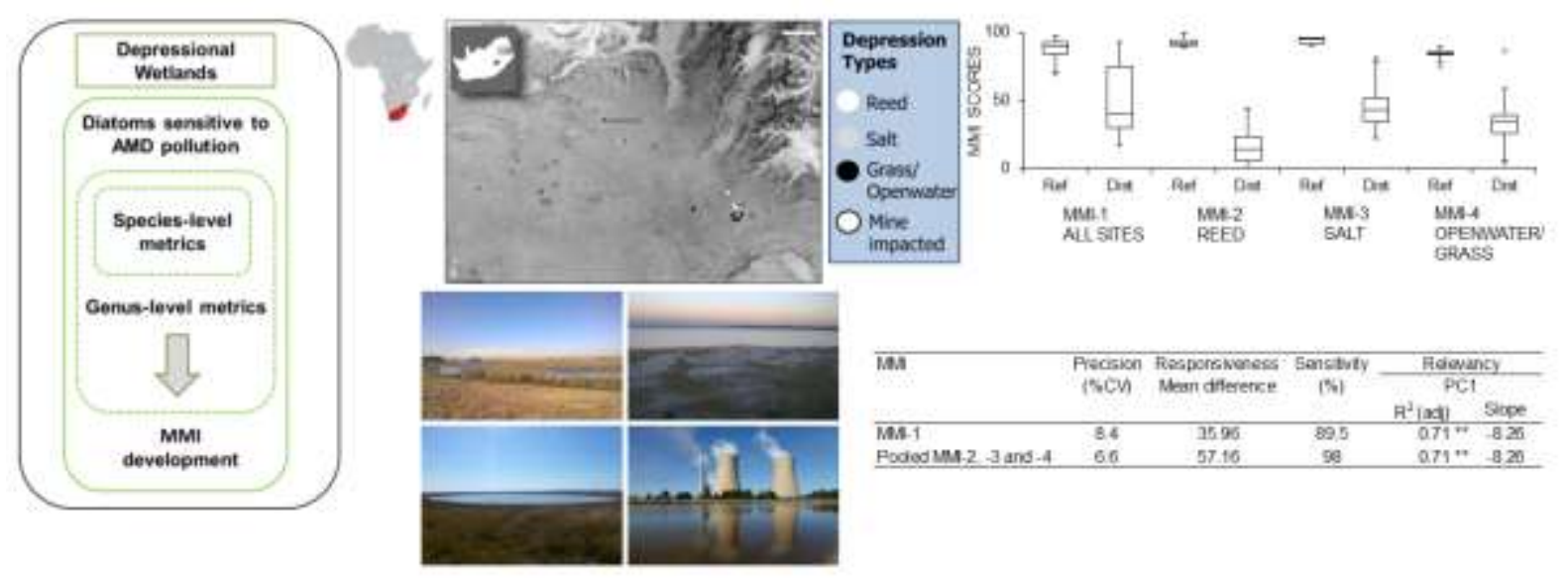

\section{Abstract}

Acid mine drainage (AMD) from coal mining in the Mpumalanga Highveld region of South Africa has caused severe chemical and biological degradation of aquatic habitats, specifically depressional wetlands, as mines use these wetlands for storage of AMD. Diatom-based multimetric indices (MMIs) to assess wetland condition have mostly been developed to assess agricultural and urban landuse impacts. No diatom MMI of wetland condition has been developed to assess AMD impacts related to mining activities. Previous approaches to diatom-based MMI development in wetlands have not accounted for natural variability. Natural variability among depressional wetlands may influence the accuracy of MMIs. Epiphytic diatom MMIs sensitive to AMD were developed for a range of depressional wetland types to account for natural variation in biological metrics. For this, we classified wetland types based on diatom typologies. A range of 4-15 final metrics were selected from a pool of $~ 140$ candidate metrics to develop the MMIs based on their: (1) broad range, (2) high separation power and (3) low correlation among metrics. Final metrics were selected from three categories: similarity to reference sites, functional groups, and taxonomic composition, which represent different aspects of diatom assemblage structure and function. MMI performances were evaluated according to their precision in distinguishing reference sites, 
responsiveness to discriminate reference and disturbed sites, sensitivity to human disturbances and relevancy to AMD-related stressors. Each MMI showed excellent discriminatory power, whether or not it accounted for natural variation. However, accounting for variation by grouping sites based on diatom typologies improved overall performance of MMIs. Our study highlights the usefulness of diatom-based metrics and provides a model for the biological assessment of depressional wetland condition in South Africa and elsewhere.

Keywords: Mining, Index of Biotic Integrity, Biological Assessment, Diatom typology, Wetland Condition

\section{Introduction}

Multimetric indices (MMIs) based on diatom assemblage responses to human disturbance have mostly been developed to assess the biological condition of lotic environments, specifically US streams and rivers (e.g., Cao et al., 2007; Potapova and Carlisle, 2011; Tao et al., 2016; Wang et al., 2005). Diatom-based MMIs developed for lentic systems have recently received increasing research attention, where efforts to develop MMIs for national-scale assessments of lakes (Stevenson et al., 2013) and ecoregional-scale assessments of freshwater wetlands (Miller et al., 2016) have benefited from US Environmental Protection Agency's National Aquatic Resource Surveys initiated programmes. On a relatively smaller scale, MMI development for diatom assemblages has been successful for statewide-scale assessments of depressional wetlands (those surrounded by upland) in the state of Florida (Lane and Brown, 2007) and for riverine and depressional wetlands in the Casco Bay watershed in Maine (Wang et al., 2006).

However, no diatom MMI developed for wetlands has controlled for effects of natural variation on index values, where natural variability of environmental factors among sites (i.e. 
factors least affected by human disturbances) can reduce accuracy of the index (Cao et al., 2007; Stoddard et al., 2008; Hawkins et al., 2010a). This is particularly vital for wetland habitats which are inherently highly variable, even within wetland types (such as depressional wetlands), which can vary significantly over small spatial scales (Bird et al., 2013). Wetlands differ widely due to intra- and inter- regional differences in naturally varying environmental factors (e.g., climate, geology, soils, topography, hydrology, water chemistry and vegetation) that can contribute to natural differences in their biological assemblages (e.g., USEPA, 2016). Consequently, surveys with high heterogeneity among wetlands will likely result in poorly performing MMIs if indices are not controlled for the effects of natural gradients, as was found by (Miller et al., 2016) when developing a diatom-based MMI for a range of northeastern US wetlands. Ecologically robust biological assessment indices should account for natural variability in biological assemblages so as to provide a more accurate assessment of deviation from reference condition (minimally disturbed conditions) as a result of human disturbances (Hawkins et al., 2000; Hughes et al., 1986).

Various approaches have been applied to MMIs to partition the effects of natural variability. One common approach is an a priori classification using geographic regionalisations, such as ecoregions, or abiotic factors such as altitude, geology, climate and water chemistry, to classify reference sites into environmentally homogenous types or classes (discrete categories) (Barbour et al., 1999). However, this approach has generally proven to be less effective in accounting for enough natural variation in assemblage composition (e.g., Hawkins et al., 2000; Heino et al., 2002; Herlihy et al., 2006) than using a biological typology approach, in which sites are grouped based on similarity in composition of biological assemblages (Davies and Jackson, 2006; Lavoie et al., 2014; Vander Laan and Hawkins, 2014). Classification by biological typology has accounted for more natural 
variability among reference sites and improved MMI accuracy than grouping sites by ecoregions (Hawkins, 2006; Tao et al., 2016).

MMIs offer a simple tool that can summarise complex biological systems, where a gradient of anthropogenic disturbance can be successfully evaluated using a collection of individual assemblage metrics combined into a single index of human disturbance (Karr and Chu, 1997). A multimetric approach can be more effective in assessing biological condition than using individual metrics because multiple metrics incorporate a variety of taxonomic and functional groups which have varying responses to different stressors and thus, can indicate the overall biological condition in a more comprehensive manner (Gerritsen, 1995; Karr, 1999).

Diatom-based MMIs to assess wetland condition have mostly been developed to quantify nutrient loading, elevated salinity and changes in $\mathrm{pH}$ resulting from agricultural and urban landuse (e.g., Lane and Brown, 2007; Miller et al., 2016; Wang et al., 2006), but no diatom index of wetland condition has been developed to quantify acid mine drainage (AMD) impacts related to mining activities.

AMD is a primary stressor in depressional wetlands of the Mpumalanga Highveld region of South Africa, where coal mines use these wetlands for dirty water storage by pumping AMD directly into the wetland (Ochieng et al., 2010). AMD can also enter the wetland via seepage and surface runoff from contaminated mine tailings dumps and stockpiles. AMD pollution arises when pyrite, a sulphur bearing mineral found in coal deposits, is exposed to oxygenated water and consequently produces sulphuric acid (Johnson and Hallberg, 2005). The acidic water becomes neutralised by dilution, and various chemical reactions with natural alkaline waters often are found in permanent depressional wetlands used to store mine wastewater in the Mpumalanga Highveld. Nevertheless, some elements have high solubilities and in such cases, persist in the water; this is particularly true for 
sulphate (McCarthy, 2011). Consequently, AMD impacted depressional wetlands in the region are typically sulphate-rich and extremely saline. Such alterations to the physical and chemical environment may render the water toxic to varying degrees and inhospitable to aquatic biota (Hirst et al., 2002; Sabater, 2000).

Numerous studies, focused mostly on streams, have demonstrated that the distribution of diatom communities can be significantly explained by dominant indicators of AMD, such as pH, alkalinity, conductivity, sulphate, and metals (e.g., Ferreira da Silva et al., 2009; Gray and Vis, 2013; Oberholster et al., 2013; Zalack et al., 2010). An effective diatom MMI used to assess the impacts of AMD has already been successfully applied to mine-impacted Appalachian streams (Gray and Vis, 2013; Pool et al., 2013). Thus, the use of diatoms as indicators of wetland condition responsive to mining impacts is a promising alternative to the traditional approach employed in South Africa, using macroinvertebrates and macrophytes, which have shown weak associations with wetland impairment (Bird and Day, 2010; Corry, in press; Day and Malan, 2010; Ferreira et al., 2012).

Depressional wetlands are one of the most valuable wetland types in the Mpumalanga Highveld region in terms of providing habitat for vulnerable species and socio-economic benefits to local communities. Remarkably, these wetlands (approximately 2600 of them in the region), have received relatively limited attention despite their importance and the everincreasing threat to these systems from rapid mining development. In this study, our primary goal was to develop an MMI for depressional wetland condition in the Mpumalanga Highveld region based on epiphytic diatom assemblages that would be sensitive to mining impacts. To account for natural variability among reference sites, separate MMIs for classes of depressional wetland types were constructed. Our objectives were (1) to evaluate the performance of MMIs in their ability to discriminate between wetland diatom communities in AMD-impacted sites and non-AMD impacted reference sites; and (2) to determine whether 
accounting for natural variation in assemblages by diatom typology based classifications will improve MMI performance. Performance of MMIs were compared to test the hypothesis that accounting for natural variation based on site classification by diatom typologies will improve MMI performance.

\section{Materials and methods}

\subsection{Study area and site selection}

Diatom assemblages of permanent depressional wetlands in the Mpumalanga Highveld region were studied because depressional wetlands used for AMD storage in this area tend to be permanently inundated. Using information provided by wetland specialists around South Africa, forty-six depressional wetlands that reflect an AMD pollution gradient based on historical water chemistry, vegetation and diatom data were selected. Sites were also selected based on inundation conditions (permanence), which were examined using Google Earth Pro and time-sequenced satellite imagery (Google, 2015) and verified with information from previous studies and local landowners. Catchment boundaries of each site were delineated based on a 5m resolution Digital Elevation Model using ArcGIS 10.1 (ESRI, 2011).

Of the forty-six wetlands selected, thirty-four sites (range $=3-309$ ha) were accessible for sampling in May-August of 2015. Sampling occurred once during the dry season to avoid possible seasonal effects on the structure and composition of diatom communities, such as differences in climate and hydrology that control wetland water chemistry, or the influence of surface runoff contaminants from other landuse activities (mostly agriculture) in the catchment (Fig. 1). Fifteen reference sites were identified based on the following criteria - no mining in the catchment, surrounded by overgrazed pastures, with the exception of one site which was surrounded by both overgrazing and dryland cultivation, and no stressors in the surface water from mining-derived groundwater contamination or pollutants associated with 
human activities. The nineteen wetlands not meeting the above criteria were classified as disturbed sites.

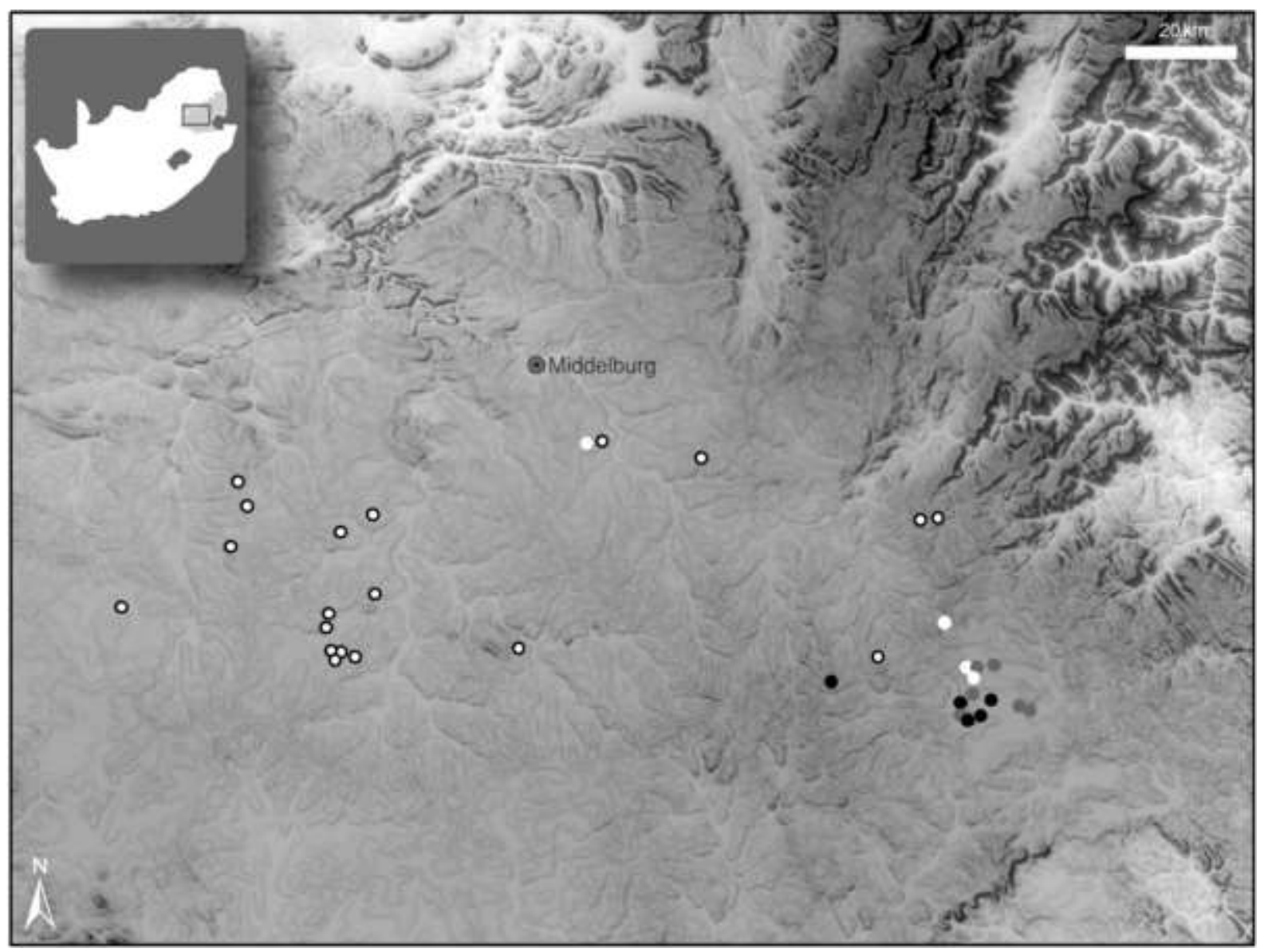

Fig.1. Map of the study area showing location of reference and disturbed sites; inset shows study area location in South Africa. Of the reference sites, the white circles with no borders represent reed depressions, grey circles are salt depressions, black circles are open-water and grass depressions combined, and the disturbed sites are represented by white circles with black borders.

\subsection{Data collection}

One sample of diatom material and surface water per site was collected in the inner part of the littoral zone. For disturbed sites, the sampling location within each wetland was selected based on proximity to visible disturbance from mining (e.g., mine-drainage discharge). Water chemistry samples were collected and physical variables were measured at the same location and time as the diatom sampling. Conductivity and $\mathrm{pH}$ were measured at each site using a 
Hach HQ40D Dual Input Multi-Parameter meter in-situ. Turbidity was measured insitu using a Hach 2100P portable turbidimeter; Secchi disk transparency was also measured. Wetland water $(1 \mathrm{~L})$ was collected in an acid-cleaned, high-density polyethylene bottle and stored in the dark on ice until return to the CSIR Environmental Laboratory in Stellenbosch, where samples were analysed for $\mathrm{NH}_{3}, \mathrm{TN}, \mathrm{TP}, \mathrm{PO}_{4}{ }^{2-}, \mathrm{Ca}^{2+}, \mathrm{Mg}^{2+}, \mathrm{Na}^{+}, \mathrm{K}^{+}, \mathrm{Cl}^{-}, \mathrm{SO}_{4}{ }^{2-}, \mathrm{F}^{-}$, dissolved organic carbon (DOC), turbidity, alkalinity and metals ( $\mathrm{Al}, \mathrm{Fe}, \mathrm{Mn}$ ) following standard procedures (APHA, 1998).

Following the preferred method for sampling diatoms in shallow lakes (Blanco and Bécares, 2006; Stenger-Kovács et al., 2007), epiphytic diatoms were sampled from one emergent macrophyte species at each site (either Phragmites australis, Typha capensis or Schoenoplectus spp.). Young stalks (4-6 fragments of stems of $10 \mathrm{~cm}$ length) were collected in the inner part of the littoral zone, $2-5 \mathrm{~cm}$ below the water surface, avoiding densely packed mats (shading effect). Stems were placed into a zip lock bag with a small amount of distilled water. Epiphytes were dislodged from all stems by shaking the samples for 2 min following Zimba and Hopson (1997) which allows for the collection of $>90 \%$ of diatoms attached to stems (the combined exposed surface area reaching ca. $300 \mathrm{~cm}^{2}$ ). For six salt depressional wetland sites devoid of vegetation, epilithic diatoms were sampled from stones (total surface area again making up ca. $300 \mathrm{~cm}^{2}$ ) according to guidance protocols described in King et al. (2006). Diatom samples were returned to the laboratory where they were acid cleaned and mounted on microscope slides. 500 frustules were counted and identified to the lowest feasible taxonomic level using standard European diatom floras (e.g., Krammer and LangeBertalot, 1986-1991; Lange-Bertalot et al., 2001; Lange-Bertalot, 2000-2002), several papers on the Southern African flora by Cholnoky, Schoeman and Archibald (e.g., Schoeman and Archibald, 1976-1980), and books and recent papers on Gomphonema taxonomy (e.g., 
Reichardt, 2015; Reichardt and Lange-Bertalot, 1999; Rose and Cox, 2014). We then checked the current nomenclature using AlgaeBase (Guiry and Guiry, 2016).

\subsection{Classification of reference sites}

An a priori classification of reference sites into depression-type groups was made based on discriminating environmental factors (least affected by human disturbances) in published studies (Allan, 1987; Allan et al., 1995; Cowan and van Riet, 1998). Sites were assigned to four depression-type groups: (1) Reed depressions - typically saline, comprised of dense central stands of emergent Phragmites, encircled by a narrow band of open water, thickly underlain with submergents Lagarosiphon and Potamogeton. (2) Salt depressions - extremely saline, comprised of hypersaline substrata, which can appear bright white due to the high reflectiveness of the salt; sedge Schoenoplectus triqueter is typically found around the shorelines. (3) Open-water depressions - fresh to slightly saline, shallow soil or exposed rock, devoid of vegetation, excluding the shorelines where grass, Cynodon dactylon, sedges (Cyperus species and Scirpus dioecus), and several Juncus species can be found. (4) Grass depressions - comprised of dense growths of hygrophilous grasses and sedges and other lowgrowing terrestrial vegetation, with similar salinities to the open-water depressions.

Next, depression-type groups were defined based on diatom typology using cluster analysis (PC-ORD 5.10; McCune and Mefford, 2006) on square-root transformed diatom assemblage data. Three depression-type groups were retained for the development of the following MMIs: (1) MM1-1 using all 15 reference sites; (2) MMI-2 using 4 reed reference depressions; (3) MMI-3 using 6 salt reference depressions; and (4) MMI-4 using 5 reference depressions for both open-water and grass depression-types combined. 


\subsection{Development of MMIs}

\subsubsection{Candidate diatom metrics}

A total of 154 candidate metrics, assigned to four categories (diversity, similarity to reference sites, functional group and taxonomic composition) were examined for possible inclusion in the MMIs, derived from Wang et al. (2005), Stevenson et al. (2013), Passy (2007a, 2007b), and Rimet and Bouchez (2012) (Supplementary Table 1). Diversity metrics included species richness, evenness, Shannon diversity and the relative abundance of the most dominant taxon in a sample (\% dominance).

Similarity to reference metrics included the number of distinct reference taxa, and \% reference and \% tolerant taxa and individuals (species typical of reference and disturbed sites); all were identified by indicator species analysis (Dufrene and Legendre, 1997) using PC-ORD 5.10. The percentage of reference taxa and individuals found in reference sites that occurred in disturbed sites, and Bray-Curtis percent similarity to reference sites (Bray and Curtis, 1957) was calculated using PRIMER 6 (Clarke and Gorley, 2006).

Candidate functional group metrics were based on two types of functional groups a), life-forms and b), ecological guilds, in accordance with Passy (Passy, 2007a, 2007b) and Rimet and Bouchez (2012) (Supplementary Table 1). Diatom taxa at the species or genus level were assigned to the various life-form groups (e.g., pioneer, pedunculate or ribbon colony) and ecological guild groups (high profile, low profile, motile or planktonic guilds). Functional group metrics were calculated as the relative abundance of taxa or individuals divided by the sum of taxa or individuals for each functional group within a sample. Similarly, taxonomic composition metrics were calculated as the relative abundance of taxa or individuals in relation to the number of taxa or individuals for each genus within a sample. 


\subsubsection{Metric selection}

Metrics were selected from the pool of candidate metrics using the following step-wise screening procedure (Stoddard et al., 2008). (1) Range test - metrics were discarded with an insufficient range; metrics with medians of 0 in both reference and disturbed sites. (2) Responsiveness test - metrics were selected with a Mann-Whitney $\mathrm{Z}$ value $\geq 2$, considered to be a strong separation power indicator between reference and disturbed sites (Stevenson et al., 2013). (3) For similar metric pairs (e.g., \% reference taxa and \% reference individuals), the metric with the highest separation power indicator (Z-value) was selected. If metric pairs shared the same Z-value, the coefficient of variance (CV) was calculated for each metric based on reference and disturbed sites and retained the metric with the lowest $\mathrm{CV}$; the lower the CV, the more precise the metric (Cao et al., 2007). (4) Redundancy test - to provide an independent set of metrics for the MMI, redundant metrics within the reference sites $(\mathrm{r} \geq$ 0.70) were identified using Spearman correlations (Hughes et al., 1998), and for redundant metric pairs, the metric with the highest Z-value was selected. Spearman correlation and the Mann-Whitney test were conducted using InfoStat (Di Rienzo et al., 2011).

\subsubsection{Metric re-scaling and MMI scoring}

To standardise the range of selected metrics, each metric was rescaled to a score between 0 and 1 following (Blocksom, 2003). The $5^{\text {th }}$ and $95^{\text {th }}$ percentile of all sites (reference and disturbed) within each metric were used. Each metric value was rescaled using the formula:

Rescaled metric value $=\frac{\text { original metric value }-5^{\text {th }}}{95^{t h}-5^{t h}}$

If rescaled metric values were less than zero, these values were adjusted to 0 and if greater than 1, we adjusted them to 1 . For metrics that increased at disturbed sites and decreased at reference sites, the rescaled metric value was subtracted from 1 to reverse the scale so that high metric values represented better biotic condition. 
The MMI was calculated using a two-step approach by (Stevenson et al., 2013) to provide a final MMI with a 0 to 100 scaling system. (1) Composite metrics were calculated for each metric category (composed of $\geq 1$ metrics) as the mean of the rescaled metric values within each metric category. (2) The MMI was then calculated as the mean of all composite metrics multiplied by 100 . This approach produces an MMI in which each metric category is given equal weight independent of the number of metrics within each category. For an MMI with only one metric category, the MMI was calculated as the mean of the rescaled metric values multiplied by 100 .

\subsection{Evaluating performance of MMIs}

The performances of the MMIs were evaluated according to four measures: precision, responsiveness, sensitivity and relevancy (Hawkins et al., 2010a; Stevenson et al., 2013; Tao et al., 2016). (1) Precision was measured by calculating the coefficient of variance (CV) for MMI values among the reference sites; thus, an MMI with a lower CV is more precise. (2) MMI responsiveness was tested by calculating the difference in mean MMI values between the reference and disturbed sites to determine the extent to which each MMI discriminated between reference and disturbed sites; the larger the difference between the mean values, the more responsive the MMI. (3) MMI sensitivity was measured as the percentage of disturbed sites that were evaluated as non-reference; that is the MMI score at each disturbed site was less than the $25^{\text {th }}$ percentile of reference site MMI values. (4) MMI relevancy was evaluated following Stevenson et al. (2013) by analysing the relationship between the MMI and the results of the first principal axis scores (PC1) from a Principal Components Analysis (PCA) of all sites using log-transformed chemical variables that discriminate reference from disturbed sites. We used two variables, $\mathrm{Ca}^{2+}$ and $\% \mathrm{SO}_{4}{ }^{2-}: \mathrm{Cl}$, which we predicted as predominant coal mining-related stressors in depressional wetlands. AMD is treated with 
lime composed of calcium hydroxide, $\mathrm{Ca}^{2+}(\mathrm{OH})_{2}$. Considerably higher concentrations of $\mathrm{Ca}^{2+}$ were observed in our disturbed sites compared to our reference sites (mean 177.6 and 17.3 $\mathrm{mg} \mathrm{L}^{-1}$, respectively, Supplementary Table 2) which potentially indicate the impact of AMD. $\mathrm{SO}_{4}{ }^{2-}$ concentrations were high in the highly disturbed sites (mean $1740.6 \mathrm{mg} \mathrm{L}^{-1}$ ) yet, similar concentrations also occurred naturally in salt depression reference sites (mean 1291 $\mathrm{mg} \mathrm{L}^{-1}$, Supplementary Table 2). For this reason, sulphate would not be a reliable indicator of AMD pollution. We did, however, observe that the ratio of $\mathrm{SO}_{4}{ }^{2-}: \mathrm{Cl}$ was consistently lower among reference sites than among mine-impacted sites (see also Abiye, 2014) and therefore we included $\mathrm{SO}_{4}{ }^{2-}: \mathrm{Cl}$, calculated as a percentage, in the PC1 disturbance gradient. Metals Fe, $\mathrm{Mn}$, and $\mathrm{Al}$ were not included as stressors for two reasons: firstly, they were found in both reference and disturbed sites in low concentrations and therefore showed poor discrimination ability; and secondly, they were correlated with the PC1 axis in the opposite direction to $\mathrm{Ca}^{2+}$ and $\% \mathrm{SO}_{4}{ }^{2-}: \mathrm{Cl}$. Including metals would, therefore, only weaken the strength of the relationship between MMIs and PC1 disturbance gradients. MMI relevancy was measured using simple linear regression where MMI values were regressed with PC1 disturbance gradients. All models were checked that they met the assumptions of linear regression including normality of residuals and homoscedasticity using R (R Development Core Team, 2008) (all assumptions were met). A well-performing MMI should be linearly correlated across the entire disturbance gradient, and in doing so, demonstrates its ability to discriminate across varying levels of degradation (Tao et al 2016, Hawkins et al 2010a). We predicted MMIs to be negatively related to the measurement of disturbance (PC1), whereby the greater the amount of variability in an MMI explained by the disturbance variables, the more relevant the MMI.

The performance of the two MMI types, one with and one without site classification, were compared. Comparing MMI-1 to MMI-2, -3, and -4 is affected by sample size 
differences, but is also conceptually unequal. MMI-1 involves all the sites and is one way to calculate an MMI, and MMI-2, -3, and -4 are all calculated the same way and together represent all the sites. MMI-1 was compared to the pooled performance results of MMI-2, -3, and -4 . The weighted average (pooled variance) results of MMI-2, -3 , and -4 were calculated by multiplying each performance result of MM1-2, -3 , and -4 by its sample size, summing those products, then dividing that sum by the sum of the number of sites for each of the MMI-2, -3, and -4. Finally, the relationship of MMI-2, -3, and -4 together with PC1 was calculated, i.e. included all the sites in the relationship to human disturbance.

\section{Results}

\subsection{Physical-chemical and diatom data}

A wide range of physico-chemical variables were observed among the reference sites (Supplementary Table 2). Open-water/grass depressions were characterised by relatively low conductivity and alkalinity (mean conductivity: $57 \mathrm{mS} \mathrm{m}{ }^{-1}$, mean alkalinity: $204 \mathrm{mg} \mathrm{L}^{-1}$ ) in contrast to the hypersaline, highly alkaline (carbonate-rich), salt depressions (mean conductivity: $1378 \mathrm{mS} \mathrm{m}^{-1}$, mean alkalinity: $2067 \mathrm{mg} \mathrm{L}^{-1}$ ). Nutrient concentrations were low at most reference sites, except for two salt depression sites, where the presence of flamingo

colonies was a likely explanation for the high nutrient loading (Max TP: $11 \mathrm{mg} \mathrm{L}^{-1}$ and Max TN: $32 \mathrm{mg} \mathrm{L}^{-1}$ ).

With regards to the diatom data, a total of thirty-four samples were analysed and 52 genera and 186 species were identified. From this total, 47 genera and 152 species were identified in disturbed sites. Of all the reference depression-types, reed depressions were the most diverse (25 genera and 70 species), followed by open-water/grass depressions (21 genera and 46 species), and salt depressions (15 genera and 32 species). Supplementary Table 3 shows the results of the indicator species analysis showing taxa to be significantly $(\mathrm{P}<$ 
0.05) present in reference (Ref) and disturbed (Dist) sites. These taxa were used to calculate the following metrics for each MMI: number of distinct reference taxa, and \% reference and $\%$ tolerant taxa and individuals.

Table 1 Final metrics used to develop composite metrics comprised of $\geq 1$ metrics within each metric category.

(x) Metrics selected for each MMI best discriminated between references and disturbed sites. Direction of metric response to disturbance is shown by + or - which represents an increase or decrease to disturbance, and (v) a variable response.

\begin{tabular}{|c|c|c|c|c|c|}
\hline Category/ Final metric & MMI-1 & MMI-2 & MMI-3 & MMI-4 & Response \\
\hline \multicolumn{6}{|l|}{ Similarity to reference sites } \\
\hline$\%$ reference taxa & $\mathrm{x}$ & $\mathrm{x}$ & $\mathrm{x}$ & $\mathrm{x}$ & - \\
\hline$\%$ tolerant taxa & $\mathrm{x}$ & $\mathrm{x}$ & $\mathrm{x}$ & $\mathrm{x}$ & + \\
\hline$\%$ similarity to reference sites & $\mathrm{x}$ & $\mathrm{x}$ & $\mathrm{x}$ & & - \\
\hline $\begin{array}{l}\text { \% reference taxa found in reference sites that occurred in } \\
\text { impaired sites }\end{array}$ & & & $\mathrm{x}$ & $\mathrm{x}$ & - \\
\hline $\begin{array}{l}\% \text { reference individuals found in reference sites that } \\
\text { occurred in impaired sites }\end{array}$ & $\mathrm{x}$ & & & & - \\
\hline No. of distinct reference taxa & & $\mathrm{x}$ & $\mathrm{x}$ & $\mathrm{x}$ & - \\
\hline \multicolumn{6}{|l|}{ Functional group } \\
\hline Mobile \% taxa & $\mathrm{x}$ & & & & - \\
\hline Adnate $\%$ taxa & & & $\mathrm{x}$ & & - \\
\hline Pad (attached to substrate) $\%$ taxa & $\mathrm{x}$ & & $\mathrm{x}$ & & + \\
\hline Non-colonial \% taxa & & & $\mathrm{x}$ & & - \\
\hline Ribbon \% taxa & & & $\mathrm{x}$ & & + \\
\hline Ribbon \% individuals & $\mathrm{x}$ & & & & + \\
\hline High profile guild $\%$ taxa & & & $\mathrm{x}$ & & + \\
\hline \multicolumn{6}{|l|}{ Taxonomic composition } \\
\hline$\%$ Encyonopsis taxa & & & $\mathrm{x}$ & & + \\
\hline$\%$ Cocconeis taxa & & & $\mathrm{x}$ & & + \\
\hline$\%$ Craticula taxa & & & $\mathrm{x}$ & & - \\
\hline$\%$ Ctenophora taxa & $\mathrm{x}$ & & $\mathrm{x}$ & & + \\
\hline$\%$ Gomphonema taxa & & & $\mathrm{x}$ & $\mathrm{x}$ & $\mathrm{v}$ \\
\hline$\%$ Nitzschia individuals & & & & $\mathrm{x}$ & - \\
\hline
\end{tabular}




\subsection{Metric screening and selection of final metrics}

Our metric screening procedure reduced candidate metrics from a pool of $\sim 140$ to a range of 4-15 final metrics to develop the MMIs (Table 1). The range test for zero median values in both reference and disturbed sites eliminated the largest number of candidate metrics for possible inclusion in the four MMIs, all of which belonged to the taxonomic composition category. The diversity category failed the screening process for all MMIs. Most diversity metrics had $|\mathrm{Z}|<2$ and thus, were eliminated by the responsiveness test (Supplementary Table 4a, b), except for MMI-2 (reed depression-types) in which diversity metrics failed the evaluation for redundancy.

\subsection{MMI performance}

To establish whether accounting for natural variation by diatom typology based site classifications improved MMI performance, evaluations in performance were compared between two MMI types, with and without site classification. A visual comparison of MMI scores was used, examining the degree of overlap between interquartile ranges and medians of MMI distributions to evaluate MMI performances (Fig. 2). All four MMIs displayed excellent discriminatory power between reference and disturbed sites by having no overlap between the interquartile ranges within reference and disturbed sites. Indeed, the entire MMI distributions within reference and disturbed sites, developed for MMI-2,-3 and -4, did not overlap, suggesting an improvement in performance using diatom typology based classification to account for natural variation among sites. 


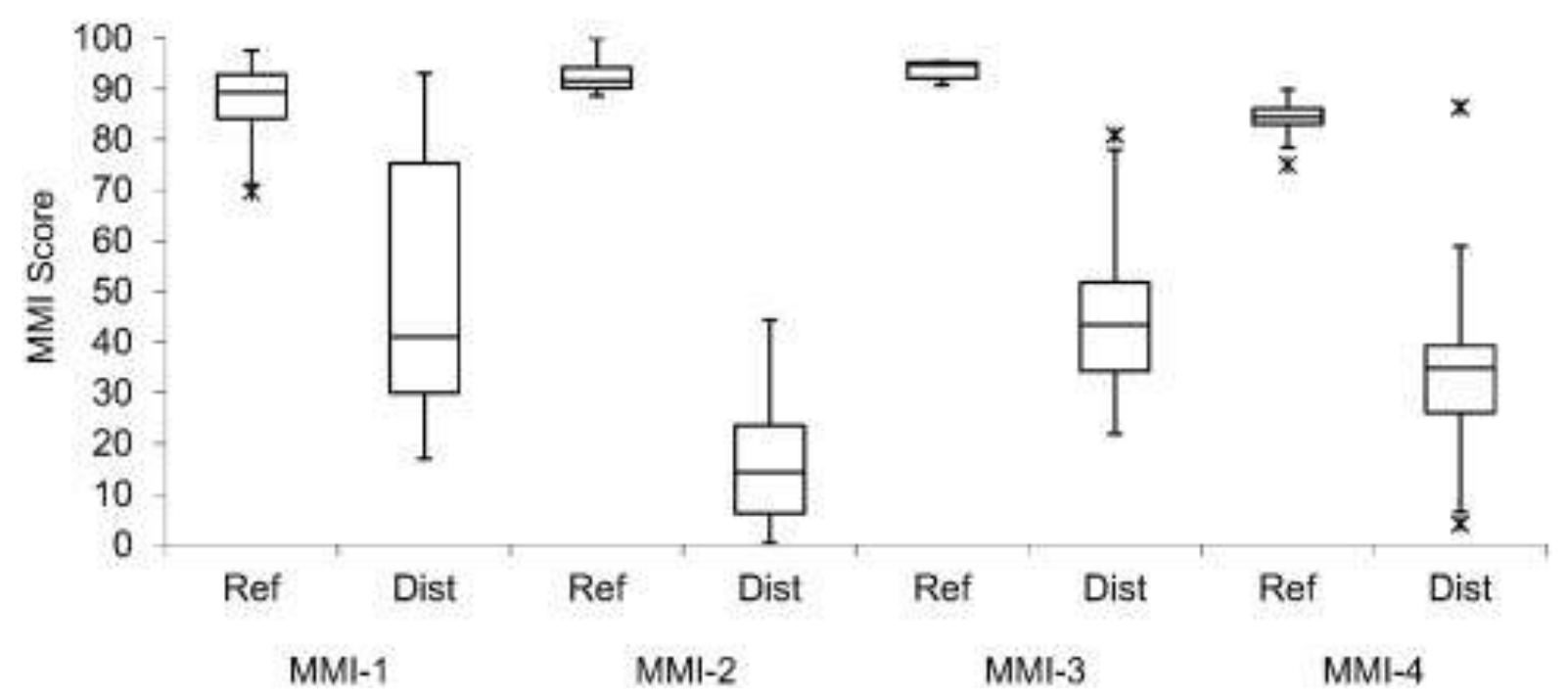

Fig. 2. Box plots showing the range of scores for four MMIs at reference (Ref) and disturbed sites (Dist) under 0-100 scaling system. MM1-1 using all 15 reference depression sites; MMI-2 using 4 reed reference depressions; MMI-3 using 6 salt reference depressions; and MMI-4 using 5 reference depressions for both openwater and grass depression-types combined. Horizontal lines represent the medians, boxes represent the interquartile ranges (25th and 75 th percentiles), whiskers represent 1.5 interquartile ranges and $*$ represent outliers.

Results of the visual comparison of MMI performance corroborated further evaluations of performance (Table 2). Site classification by diatom typology increased precision of MMIs indicated by lower CVs (6.6\%) than an MMI without site classification (8.4\%). An MMI with site classification had considerably greater responsiveness than an MMI without site grouping, as indicated by larger differences in mean values between the reference and disturbed sites (from 35.96 to 57.16). The two types of MMIs showed high sensitivity, although an MMI with site classification had better sensitivity (98.2\%) than without classification $(89.5 \%)$. The results of the linear regressions indicated a strong negative correlation between the human disturbance gradient and the MMIs $\left(\mathrm{PC} 1 ; \mathrm{R}^{2}{ }_{\text {adj }}=\right.$ $0.71)$. 
Table 2 Results of MMI performance based on: precision (coefficient of variation (\%CV) of reference site index values), responsiveness (mean difference for comparison between mean reference and disturbed site index values), sensitivity (\% of disturbed sites evaluated as in non-reference condition), and relevancy $\left(\mathrm{R}^{2}\right.$ adj as explained variance of MMI regression with principal component axis 1 (PC1) disturbance gradient. Significance of each relationship is indicated by $* \mathrm{P} \leq 0.01$ and $* * \mathrm{P}<0.0001$. The table displays the pooled (weighted average) results of MMI-2, -3 and -4 .

\begin{tabular}{lcccccc}
\hline MMI & $\begin{array}{c}\text { Precision } \\
(\% \mathrm{CV})\end{array}$ & $\begin{array}{c}\text { Responsiveness } \\
\text { Mean }\end{array}$ & $\begin{array}{c}\text { Sensitivity } \\
\text { difference }\end{array}$ & $(\%)$ & \multicolumn{3}{c}{ Relevancy } \\
\cline { 4 - 7 } & 8.4 & 35.96 & & \multicolumn{2}{c}{ PC1 } \\
\hline MMI-1 & 6.6 & 57.16 & 89.5 & 0.71 & $* *$ & -8.26 \\
MMI-2, -3 and -4 & & 98 & 0.71 & $* *$ & -8.26 \\
\hline
\end{tabular}

Three wetland condition classes were established based on the $25^{\text {th }}$ and the $5^{\text {th }}$ percentiles of the reference-site distribution of MMI scores, benchmarks recommended by Paulsen et al. (2008): good (scores $>25$ th $\%$ of the reference distribution), fair (scores between 5 th $\%$ and 25 th $\%$ of the distribution), poor (scores $<5$ th $\%$ of the distribution) (Table 3 ). Based on these category scores, all four indices classified $74-100 \%$ of disturbed sites as Poor, $16 \%$ as Fair, and $6-11 \%$ as Good.

Table 325 th and 5th percentiles of the reference-site distribution of MMI scores which can be used as benchmarks to partition sites into depressional wetland condition categories Good $(>25$ th $\%$ of the reference distribution), Fair (between 25th\% and 5th\%) and Poor $(<5$ th $\%$ of the distribution). Number of sites that were categorised as Good, Fair, and Poor are shown for each MMI for reference (Ref) and disturbed (Dist) sites.

\begin{tabular}{lcccccc}
\hline MMI & 25th\% & 5th\% & Good & Fair & Poor & Total \\
\hline MMI-1 & 84.2 & 76.1 & 2 & 3 & 14 & 19 \\
MMI-2 & 90.2 & 88.9 & 0 & 0 & 19 & 19 \\
MMI-3 & 92.1 & 90.9 & 0 & 0 & 19 & 19 \\
MMI-4 & 83.1 & 76.6 & 1 & 0 & 18 & 19 \\
\hline
\end{tabular}




\section{Discussion}

\subsection{Metric selection}

MMIs were developed based on epiphytic diatoms that provided a significant negative linear response to a gradient of human disturbance in depressional wetlands. For this we used metrics from three categories: similarity to reference sites, functional groups and taxonomic composition, reflecting different aspects of assemblage structure and function.

Metrics most responsive to discriminate between reference and disturbed sites (i.e. those with the highest $\mathrm{Z}$-value) were generally higher for species-level metrics (e.g., \% reference and $\%$ tolerant taxa, $\%$ similarity to reference sites) than for genus-level metrics within the functional-group and taxonomic composition category (Supplementary Table 4). Similar observations were reported by Stevenson et al. (2013) when developing an MMI of lake diatom condition, who expected species-level metrics to be more responsive because species-level is generally associated with lower genetic and physiological variability than with higher taxonomic levels. Regardless, many genus-level metrics showed significant ability to discriminate reference from disturbed sites, as was also found by Stevenson et al. (2013) and investigators of depressional wetland condition (Lane, 2007; Wang et al., 2006). Our results are also consistent with those for macroinvertebrate assemblages (Firmiano et al., 2017; Silva et al., 2016; Whittier and Van Sickle, 2010). Genus-level taxonomy does not require high-level species identification which can be time consuming and require specialised taxonomic expertise, which in South Africa is largely lacking (Dalu and Froneman, 2016). The use of genus-level metrics may therefore allow for a simplified, time and cost effective assessment of wetland condition while maintaining important ecological information.

Of the final metrics useful in identifying heavily AMD impacted depressional wetlands in this study, five of those metrics were important in assessing AMD polluted 
Appalachian streams (Zalack et al., 2010). These five metrics were all from the similarity to reference site category, including $\%$ reference and $\%$ tolerant taxa, $\%$ similarity to reference sites and number of distinct references taxa; and have been recognised as being sensitive to a range of anthropogenic disturbances (Stevenson et al., 2013, 2008; Stevenson and Smol, 2003; Wang et al., 2006, 2005). As was expected from the literature, these metrics showed negative responses to increasing human disturbance, except for $\%$ tolerant taxa, which showed the opposite trend.

The response of diatom functional groups and taxonomic composition to anthropogenic disturbances (typically nutrient enrichment) has been mostly investigated in running waters, while no studies have examined their response to AMD pollution in lentic waters, as carried out in this study for the Mpumalanga Highveld depressional wetlands. We found that in MMI-3 (salt depressions), increasing AMD impacts were associated with an increase in attached diatoms, either by mucilage pad, dominated by Ctenophora and Encyonopsis, or by valve face, adnate diatoms, dominated by Cocconeis, as well as an increase in pad-attaching, ribbon-shaped colonies (comprised of Synedra fasciculata). These results are in line with other studies that have reported the same genera in highly disturbed environments (e.g., B-Béres et al., 2014; Passy, 2007a; Stenger-Kovács et al., 2013; Wang et al., 2006), including AMD altered waters (e.g., Archibald and Taylor, 2007; Luís et al., 2009; Potapova and Charles, 2003). A positive correlation was also observed between AMD pollution and high profile diatoms which include Gomphonema, Ctenophora taxa and Synedra fasciculata. Yet, in MMI-4 (open-water/grass depressions), Gomphonema responded inversely (negatively) to increasing pollution. Gomphonema taxa are widely acknowledged as ubiquitous with a wide morphological range and a broad ecological tolerance, found in polluted waters but also a wide variety of water qualities (e.g., Abarca et al., 2014; Jüttner et al., 2013; Rose and Cox, 2014). Different species of the same genera can vary greatly in 
environmental sensitivities and tolerances (Hill et al., 2001). This may explain the lack of sensitivity of Gomphonema to discriminate disturbed wetlands in MMI-1, which was developed from a range of depression reference types including salt and open-water/grass depressions. Thus, we highlight the importance of accounting for natural differences among wetland types when developing an MMI of wetland condition. The response of functional and taxonomic groups to human disturbance for a given wetland type may improve our understanding of how species diversity influences ecosystem processes (Nock et al., 2016), which may otherwise be masked in an MMI that does not control for natural variation among wetlands. Exactly what physiological mechanisms govern interactions between diatom functional groups and levels of AMD stressors in depressional wetlands are, however, still not known and deserve further investigation.

\subsection{MMI performance}

All MMIs were excellent indicators of disturbance in depressional wetlands, as shown by the non-overlapping interquartile ranges within reference and disturbed categories which implies high discrimination efficiency (Barbour et al., 1996). Further evaluations of MMI performance demonstrated that our MMIs, whether controlled for natural variation or not, performed considerably well. However, overall MMI performance improved, particularly the precision, responsiveness and sensitivity to human disturbances, when sites were classified by diatom assemblages to account for natural variation. Precision of MMIs with and without classification, indicated by the CVs, were low compared to other diatom MMIs (e.g., Tao et al., 2016: CV 14.8-30.7\%; Cao et al., 2007: 13-14\%). This suggests that there was low natural variability within and among reference depression types.

Accurate biological assessments should account for the natural variability in biological metrics (Cao et al., 2007) and one of the most effective approaches to control for 
natural variation is using biological typologies. Indeed, Tao et al. (2016), studying US streams, showed site classification by diatom assemblages gave a better MMI performance than geographic stratifications (e.g., ecoregions). Similarly, other authors (e.g., Hawkins and Vinson, 2000; Snelder et al., 2012; Van Sickle and Hughes, 2000) have demonstrated for invertebrate and fish assemblages, that classification by biological typology revealed stronger site classifications than by ecoregions and other geographic regionalisations (e.g. hydrological catchments). The fact that grouping by biological typology accounted for more of the natural variation in assemblages than ecoregions is not surprising, since grouping by ecoregion is based on the entire ecosystem, which includes biotic and abiotic components, rather than grouping by typology which is based on one ecosystem component (Tao et al., 2016).

Alternatively, using a predicted site-specific modelling approach, which is suitable for larger reference datasets than ours, has proven extremely effective for partitioning out the effects of natural variability among diatom assemblages (e.g., Cao et al., 2007), fish (de Carvalho et al., 2017; Oberdorff et al., 2002) and macroinvertebrate assemblages (Hawkins et al., 2010a; Moya et al., 2011; Pereira et al., 2016), including those related to seasonal effects (Chen et al., 2014; Macedo et al., 2016). Classification and regression trees (CART) have been employed to remove effects of natural variation from individual metrics (Cao et al., 2007). MMIs based on predictive models may be preferable over typological approaches because of their ability to establish site-specific thresholds, which may lead to more appropriate management decisions (Hawkins et al., 2010b; Mazor et al., 2016). This approach may also be more advantageous for further MMI development in the Mpumalanga Highveld, where an MMI with site-specific models for depressional wetlands in this region may be easier to implement than having to use an MMI for a specific wetland type, as presented here. However, this would demand many more reference sites than were accessible for this study. 


\subsection{Priorities for future research}

Our study has two important limitations, firstly, the relatively small sample size, preventing the use of a separate dataset to test the MMIs, as suggested by other authors (e.g., Stoddard et al., 2008; Wang et al., 2005; Zalack et al., 2010). Whereas our MMI performances showed considerably high precision and accuracy, we need to sample additional sites in the region to test and evaluate their applicability to coal mining altered depressional wetlands. Secondly, sampling in one season did not allow for identifying natural temporal variation in diatom assemblages. Although our study wetlands were permanent, and therefore relatively stable compared to seasonally-fluctuating temporary wetlands (Calhoun et al., 2016), the effects of seasonal changes on environmental factors, such as temperature, organic matter availability and catchment runoff, may directly or indirectly influence diatom assemblage structure in permanent depressional wetlands. A robust MMI should account for both natural spatial and temporal variation in assemblages to allow for accurate assessment of site condition and repeatable sampling, independent of time (Blocksom, 2003). Our standardised sampling protocol and index methodology enables future research to build on this database by sampling more reference and disturbed sites, and more seasons that will include greater natural variation and help create an assessment tool that performs well across a range of environmental settings.

Eutrophication related to agricultural practices is another major stressor affecting the condition of depressional wetlands in the Mpumalanga Highveld. It would be useful to develop an MMI based on metrics that each responds to a different type of stressor indicative of AMD pollution and agricultural impacts, such as nutrient loading and pesticide contamination. This may help elucidate how AMD pollution affects depressional wetland condition with high and low agricultural impacts, thus providing an important tool for resource managers and relevant stakeholders. 


\section{Conclusions}

This study developed diatom-based MMIs sensitive to coal mining impairment for permanent depressional wetlands in the Mpumalanga Highveld region. All MMIs performed considerably well, although accounting for natural variation by diatom typology site classification increased overall MMI performance. This is a preliminary approach and for further improvement in MMIs for depressional wetlands in the region and elsewhere, we recommend an approach that accounts for natural gradients. The strong ecological responses of epiphytic diatom assemblages to AMD pollution, measured by changes in diatom structure and function, suggests that with further research, diatom assemblages offer a viable alternative in the biological assessment of depressional wetlands in South Africa, where the use of other types of biological indicators have proven to be ineffective. The metrics presented here may be most suitable for regional use in optimising wetland conservation in the context of management, protection and rehabilitation, but may also be transferable among regions, although this would require further testing.

\section{Acknowledgements}

Luisa Riato was supported by a Coaltech Research Association Fellowship. We thank the CSIR for assistance with research expenses and technical support, Scott Driskill for the cartographic design and R. Jan Stevenson and the three anonymous reviewers for their valuable input on the manuscript.

\section{References}

Abarca, N., Jahn, R., Zimmermann, J., Enke, N., 2014. Does the Cosmopolitan Diatom Gomphonema parvulum (Kützing) Kützing Have a Biogeography? PLoS ONE 9, e86885. 
Abiye, T., 2014. Hydrogeochemical footprint as a result of mining activities in the Johannesburg area. Technical Report. School of Geosciences, University of the Witwatersrand.

Allan, D.G., 1987. Transvaal Highveld pans. African Wildlife 41, 233-235.

Allan, D.G., Seaman, M.T., Kaletja, B., 1995. The endoheric depression wetlands of South Africa, in: Wetlands of South Africa, Ed. G.I. Cowan. Department of Environmental Affairs and Tourism, Pretoria, South Africa, pp. 75-101.

American Public Health Association (APHA), 1998. Standard Methods for the Examination of Water and Wastewater. American Public Health Association, Washington, DC.

Archibald, C.G.M., Taylor, J.C., 2007. The assessment of diffuse pollution from acid-mine drainage using an updated and revised diatom assessment procedure as an added-value bio-monitoring tool. Water Sci. Technol. 55, 151.

Barbour, M.T., Gerritsen, J., Griffith, G.E., Frydenborg, R., McCarron, E., White, J.S., Bastian, M.L., 1996. A Framework for Biological Criteria for Florida Streams Using Benthic Macroinvertebrates. J. North Am. Benthol. Soc. 15, 185-211.

Barbour, M.T., Gerritsen, J., Snyder, B.D., Stribling, J.B., 1999. Rapid bioassessment protocols for use in streams and rivers: periphyton, benthic macroinvertebrates, and fish. 2nd edition. EPA 841-B-99-002 Office of Water, US Environmental Protection Agency, Washington, DC.

B-Béres, V., Török, P., Kókai, Z., Krasznai, E.T., Tóthmérész, B., Bácsi, I., 2014. Ecological diatom guilds are useful but not sensitive enough as indicators of extremely changing water regimes. Hydrobiologia 738, 191-204.

Bird, M.S., Day, J.A., 2010. Aquatic invertebrates as indicators of human impacts in South African wetlands.Wetland Health and Importance Research Programme (Project No. K5/1584). Water Research Commission (WRC), Pretoria, South Africa.

Bird, M.S., Mlambo, M.C., Day, J.A., 2013. Macroinvertebrates as unreliable indicators of human disturbance in temporary depression wetlands of the south-western Cape, South Africa. Hydrobiologia 720, 19-37.

Blanco, S., Bécares, E., 2006. Método de muestreo de diatomeas epífitas en lagunas para la aplicación de la Directiva Marco del Agua. Tecnol Agua 277, 42-47. 
Blocksom, K.A., 2003. A Performance Comparison of Metric Scoring Methods for a Multimetric Index for Mid-Atlantic Highlands Streams. Environ. Manage. 31, 670-682.

Bray, J.R., Curtis, J.T., 1957. An Ordination of the Upland Forest Communities of Southern Wisconsin. Ecol. Monogr. 27, 325-349.

Calhoun, A.J.K., Mushet, D.M., Bell, K.P., Boix, D., Fitzsimons, J.A., Isselin-Nondedeu, F., 2016. Temporary wetlands: challenges and solutions to conserving a "disappearing" ecosystem. Biol. Conserv.

Cao, Y., Hawkins, C.P., Olson, J., Kosterman, M.A., 2007. Modeling natural environmental gradients improves the accuracy and precision of diatom-based indicators. J. North Am. Benthol. Soc. $26,566-585$.

Chen, K., Hughes, R.M., Xu, S., Zhang, J., Cai, D., Wang, B., 2014. Evaluating performance of macroinvertebrate-based adjusted and unadjusted multi-metric indices (MMI) using multiseason and multi-year samples. Ecol. Indic. 36, 142-151.

Clarke, K.R., Gorley, R.N., 2006. Primer v6: user manual/tutorial. Plymouth: Primer-E.

Corry, F., in press. Development of a tool for Assessment of the Environmental Condition of Wetlands Using Macrophytes. Water Research Commission, Pretoria, South Africa.

Cowan, G.I., van Riet, W., 1998. A directory of South African wetlands. Department of Environmental Affairs and Tourism, Pretoria, South Africa.

Dalu, T., Froneman, P.W., 2016. Diatom-based water quality monitoring in southern Africa: challenges and future prospects. Water SA 42, 551.

Davies, S.P., Jackson, S.K., 2006. The biological condition gradient: a descriptive model for interpreting change in aquatic ecosystems. Ecol. Appl. Publ. Ecol. Soc. Am. 16, 1251-1266.

Day, E., Malan, H., 2010. Tools and Metrics for Assessment of Wetland Environmental Condition and Socio-Economic Importance Handbook to the WHI Research Programme (Project No. TT 433/09). Water Research Commission (WRC), Pretoria, South Africa.

de Carvalho, D.R., Leal, C.G., Junqueira, N.T., de Castro, M.A., Fagundes, D.C., Alves, C.B.M., Hughes, R.M., Pompeu, P.S., 2017. A fish-based multimetric index for Brazilian savanna streams. Ecol. Indic. 77, 386-396. 
Di Rienzo, J.A., Casanoves, F., Balzarini, M.G., Gonzalez, L., Tablada, M., Robledo, C.W., 2011. InfoStat. Córdoba: Universidad Nacional de Córdoba.

Dufrene, M., Legendre, P., 1997. Species Assemblages and Indicator Species: The Need for a Flexible Asymmetrical Approach. Ecol. Monogr. 67, 345-366.

ESRI, 2011. ArcGIS Desktop: Release 10.1 Redlands, CA: Environmental Systems Research Institute.

Ferreira da Silva, E., Almeida, S.F.P., Nunes, M.L., Luís, A.T., Borg, F., Hedlund, M., de Sá, C.M., Patinha, C., Teixeira, P., 2009. Heavy metal pollution downstream the abandoned Coval da Mó mine (Portugal) and associated effects on epilithic diatom communities. Sci. Total Environ. 407, 5620-5636.

Ferreira, M., Wepener, V., Vuren, J. van, 2012. Aquatic invertebrate communities of perennial pans in Mpumalanga, South Africa: a diversity and functional approach. Afr. Invertebr. 53, 751-768. Firmiano, K.R., Ligeiro, R., Macedo, D.R., Juen, L., Hughes, R.M., Callisto, M., 2017. Mayfly bioindicator thresholds for several anthropogenic disturbances in neotropical savanna streams. Ecol. Indic. 74, 276-284.

Gerritsen, J., 1995. Additive Biological Indices for Resource Management. J. North Am. Benthol. Soc. $14,451-457$.

Google, 2015. Google Earth. Google, Inc., Mountain View, CA.

Gray, J.B., Vis, M.L., 2013. Reference diatom assemblage response to restoration of an acid mine drainage stream. Ecol. Indic. 29, 234-245.

Guiry, M.D., Guiry, G.M., 2016. AlgaeBase. World-wide electronic publication, National University of Ireland, Galway. http://www.algaebase.org; searched on 27 January 2016.

Hawkins, C.P., 2006. Quantifying biological integrity by taxonomic completeness: its utility in regional and global assessments. Ecol. Appl. 1277-1294.

Hawkins, C.P., Cao, Y., Roper, B., 2010a. Method of predicting reference condition biota affects the performance and interpretation of ecological indices. Freshw. Biol. 55, 1066-1085. 
Hawkins, C.P., Norris, R.H., Gerritsen, J., Hughes, R.M., Jackson, S.K., Johnson, R.K., Stevenson, R.J., 2000. Evaluation of the use of landscape classifications for the prediction of freshwater biota: synthesis and recommendations. J. North Am. Benthol. Soc. 19, 541-556.

Hawkins, C.P., Olson, J.R., Hill, R.A., 2010b. The reference condition: predicting benchmarks for ecological and water-quality assessments. J. North Am. Benthol. Soc. 29, 312-343.

Hawkins, C.P., Vinson, M.R., 2000. Weak correspondence between landscape classifications and stream invertebrate assemblages: implications for bioassessment. J. North Am. Benthol. Soc. $19,501-517$.

Heino, J., Muotka, T., Paavola, R., Hämäläinen, H., Koskenniemi, E., 2002. Correspondence between regional delineations and spatial patterns in macroinvertebrate assemblages of boreal headwater streams. J. North Am. Benthol. Soc. 21, 397-413.

Herlihy, A.T., Hughes, R.M., Sifneos, J.C., 2006. National clusters of fish species assemblages in the conterminous United States and their relationship to existing landscape classification schemes, Ed. Hughes, R.M., Wang, L. \& Seelbach, P.W., in: Influences of Landscapes on Stream Habitats and Ecological Assemblages. American Fisheries Society Symposium 48. American Fisheries Society, Bethesda, Maryland, pp. 87-112.

Hill, B.H., Stevenson, R.J., Pan, Y., Herlihy, A.T., Kaufmann, P.R., Johnson, C.B., 2001. Comparison of correlations between environmental characteristics and stream diatom assemblages characterized at genus and species levels. J. North Am. Benthol. Soc. 20, 299-310.

Hirst, H., Jüttner, I., Ormerod, S.J., 2002. Comparing the responses of diatoms and macroinvertebrates to metals in upland streams of Wales and Cornwall. Freshw. Biol. 47, 17521765.

Hughes, R.M., Kaufmann, P.R., Herlihy, A.T., Kincaid, T.M., Reynolds, L., Larsen, D.P., 1998. A process for developing and evaluating indices of fish assemblage integrity. Can. J. Fish. Aquat. Sci. 55, 1618-1631.

Hughes, R.M., Larsen, D.P., Omernik, J.M., 1986. Regional reference sites: a method for assessing stream potentials. Environ. Manage. 10, 629-635. 
Johnson, D.B., Hallberg, K.B., 2005. Acid mine drainage remediation options: a review. Sci. Total Environ. 338, 3-14.

Jüttner, I., Ector, L., Reichardt, E., Van de Vijver, B., Jarlman, A., Krokowski, J., Cox, E.J., 2013. Gomphonema varioreduncum sp. nov., a new species from northern and western Europe and a reexamination of Gomphonema exilissimum. Diatom Res. 28, 303-316.

Karr, J.R., 1999. Defining and measuring river health. Freshw. Biol. 41, 221-234.

Karr, J.R., Chu, E.W., 1997. Biological Monitoring and Assessment: Using Multimetric Indexes Effectively. EPA 235-R97-001. University of Washington, Seattle.

King, L., Clarke, G., Bennion, H., Kelly, M., Yallop, M., 2006. Recommendations for sampling littoral diatoms in lakes for ecological status assessments. J. Appl. Phycol. 18, 15-25.

Krammer, K., Lange-Bertalot, H., 1986-1991. Bacillariaceae. In Susswasserflora von Mitteleuropa. Eds H. Ettl, J. Gerloff, H. Heynig and D. Mollenhauer. Spektrum Akademischer Verlag, Heidelberg: 1-2458.

Lane, C.R., 2007. Assessment of Isolated Wetland Condition in Florida Using Epiphytic Diatoms at Genus, Species, and Subspecies Taxonomic Resolution. EcoHealth 4, 219-230.

Lane, C.R., Brown, M.T., 2007. Diatoms as indicators of isolated herbaceous wetland condition in Florida, USA. Ecol. Indic. 7, 521-540.

Lange-Bertalot, H. (Ed), 2000-2002. Diatoms of Europe. Diatoms of the European Inland Waters and Comparable Habitats. Vols. I-IV, Diatoms of Europe. A. R. G. Gantner Verlag K. G: Ruggell.

Lange-Bertalot, H., Podzorski, A., Lange-Bertalot, H., 2001. Navicula sensu stricto, 10 genera separated from Navicula sensu lato, Frustulia, Diatoms of Europe. Gantner, Ruggell/Liechtenstein.

Lavoie, I., Campeau, S., Zugic-Drakulic, N., Winter, J.G., Fortin, C., 2014. Using diatoms to monitor stream biological integrity in Eastern Canada: An overview of 10 years of index development and ongoing challenges. Sci. Total Environ. 475, 187-200.

Luís, A.T., Teixeira, P., Almeida, S.F.P., Ector, L., Matos, J.X., Ferreira da Silva, E.A., 2009. Impact of Acid Mine Drainage (AMD) on Water Quality, Stream Sediments and Periphytic Diatom 
Communities in the Surrounding Streams of Aljustrel Mining Area (Portugal). Water. Air. Soil Pollut. 200, 147-167.

Macedo, D.R., Hughes, R.M., Ferreira, W.R., Firmiano, K.R., Silva, D.R.O., Ligeiro, R., Kaufmann, P.R., Callisto, M., 2016. Development of a benthic macroinvertebrate multimetric index (MMI) for Neotropical Savanna headwater streams. Ecol. Indic. 64, 132-141.

Mazor, R.D., Rehn, A.C., Ode, P.R., Engeln, M., Schiff, K.C., Stein, E.D., Gillett, D.J., Herbst, D.B., Hawkins, C.P., 2016. Bioassessment in complex environments: designing an index for consistent meaning in different settings. Freshw. Sci. 35, 249-271.

McCarthy, T.S., 2011. The impact of acid mine drainage in South Africa. South Afr. J. Sci. 107. doi:10.4102/sajs.v107i5/6.712

McCune, B., Mefford, M.J., 2006. PC-ORD. Multivariate analysis of ecological data. Version 5.10. MjM Software Design, Gleneden Beach, Oregon.

Miller, K.M., Mitchell, B.R., McGill, B.J., 2016. Constructing multimetric indices and testing ability of landscape metrics to assess condition of freshwater wetlands in the Northeastern US. Ecol. Indic. 66, 143-152.

Moya, N., Hughes, R.M., Domínguez, E., Gibon, F.-M., Goitia, E., Oberdorff, T., 2011. Macroinvertebrate-based multimetric predictive models for evaluating the human impact on biotic condition of Bolivian streams. Ecol. Indic. 11, 840-847.

Nock, C.A., Vogt, R.J., Beisner, B.E., 2016. Functional Traits, in: John Wiley \& Sons Ltd (Ed.), eLS. John Wiley \& Sons, Ltd, Chichester, UK, pp. 1-8.

Oberdorff, T., Pont, D., Hugueny, B., Porcher, J.-P., 2002. Development and validation of a fishbased index for the assessment of "river health" in France. Freshw. Biol. 47, 1720-1734.

Oberholster, P.J., Genthe, B., Hobbs, P., Cheng, P.H., de Klerk, A.R., Botha, A.-M., 2013. An ecotoxicological screening tool to prioritise acid mine drainage impacted streams for future restoration. Environ. Pollut. 176, 244-253.

Ochieng, G.M., Seanego, E.S., Nkwonta, O.I., 2010. Impacts of mining on water resources in South Africa: A review. Sci. Res. Essays 5, 3351-3357. 
Passy, S.I., 2007a. Diatom ecological guilds display distinct and predictable behavior along nutrient and disturbance gradients in running waters. Aquat. Bot. 86, 171-178.

Passy, S.I., 2007b. Community analysis in stream biomonitoring: what we measure and what we don’t. Environ. Monit. Assess. 127, 409-417.

Paulsen, S.G., Mayio, A., Peck, D.V., Stoddard, J.L., Tarquinio, E., Holdsworth, S.M., Sickle, J.V., Yuan, L.L., Hawkins, C.P., Herlihy, A.T., Kaufmann, P.R., Barbour, M.T., Larsen, D.P., Olsen, A.R., 2008. Condition of stream ecosystems in the US: an overview of the first national assessment. J. North Am. Benthol. Soc. 27, 812-821.

Pereira, P.S., Souza, N.F., Baptista, D.F., Oliveira, J.L.M., Buss, D.F., 2016. Incorporating natural variability in the bioassessment of stream condition in the Atlantic Forest biome, Brazil. Ecol. Indic. 69, 606-616.

Pool, J.R., Kruse, N.A., Vis, M.L., 2013. Assessment of mine drainage remediated streams using diatom assemblages and biofilm enzyme activities. Hydrobiologia 709, 101-116.

Potapova, M., Carlisle, R., 2011. Development and Application of Indices to Assess the Condition of Benthic Algal Communities in U.S. Streams and Rivers. US Geological Survey Open File Report, 2011-1126.

Potapova, M., Charles, D.F., 2003. Distribution of benthic diatoms in US rivers in relation to conductivity and ionic composition. Freshw. Biol. 48, 1311-1328.

R Development Core Team, 2008. R: A language and environment for statistical computing. R Foundation for Statistical Computing. Vienna, Austria.

Reichardt, E., 2015. Gomphonema gracile Ehrenberg sensu stricto et sensu auct. (Bacillariophyceae): A taxonomic revision*. Nova Hedwig. 101, 367-393.

Reichardt, E., Lange-Bertalot, H. (Eds.), 1999. Zur Revision der Gattung Gomphonema: die Arten um G. affine/insigne, G. angustatum/micropus, G. acuminatum sowie gomphonemoide Diatomeen aus dem Oberoligozän in Böhmen, Iconographia diatomologica Taxonomy. Koeltz Scientific Books, Königstein.

Rimet, F., Bouchez, A., 2012. Life-forms, cell-sizes and ecological guilds of diatoms in European rivers. Knowl. Manag. Aquat. Ecosyst. 01. 
Rose, D., Cox, E.J., 2014. What constitutes Gomphonema parvulum? Long-term culture studies show that some varieties of G. parvulum belong with other Gomphonema species. Plant Ecol. Evol. $147,366-373$.

Sabater, S., 2000. Diatom communities as indicators of environmental stress in the Guadiamar River, S-W. Spain, following a major mine tailings spill. J. Appl. Phycol. 12, 113-124.

Schoeman, F.R., Archibald, R.E.M., 1976-1980. The Diatom Flora of Southern Africa. National Institute for Water Research, CSIR Special Report WAT 50, Pretoria, South Africa.

Silva, D.R.O., Ligeiro, R., Hughes, R.M., Callisto, M., 2016. The role of physical habitat and sampling effort on estimates of benthic macroinvertebrate taxonomic richness at basin and site scales. Environ. Monit. Assess. 188, 340.

Snelder, T., Ortiz, J.B., Booker, D., Lamouroux, N., Pella, H., Shankar, U., 2012. Can bottom-up procedures improve the performance of stream classifications? Aquat. Sci. 74, 45-59.

Stenger-Kovács, C., Buczkó, K., Hajnal, É., Padisák, J., 2007. Epiphytic, littoral diatoms as bioindicators of shallow lake trophic status: Trophic Diatom Index for Lakes (TDIL) developed in Hungary. Hydrobiologia 589, 141-154.

Stenger-Kovács, C., Lengyel, E., Crossetti, L.O., Üveges, V., Padisák, J., 2013. Diatom ecological guilds as indicators of temporally changing stressors and disturbances in the small Tornastream, Hungary. Ecol. Indic. 24, 138-147.

Stevenson, R.J., Pan, Y., Manoylov, K.M., Parker, C.A., Larsen, D.P., Herlihy, A.T., 2008. Development of diatom indicators of ecological conditions for streams of the western US. J. North Am. Benthol. Soc. 27, 1000-1016.

Stevenson, R.J., Smol, J.P., 2003. Use of algae in environmental assessments, in: Freshwater Algae of North America, Ed. John D. Wehr, Robert G. Sheath and R. Patrick Kociolek. Cambridge University Press, Cambridge, pp. 775-804.

Stevenson, R.J., Zalack, J.T., Wolin, J., 2013. A multimetric index of lake diatom condition based on surface-sediment assemblages. Freshw. Sci. 32, 1005-1025. 
Stoddard, J.L., Herlihy, A.T., Peck, D.V., Hughes, R.M., Whittier, T.R., Tarquinio, E., 2008. A process for creating multimetric indices for large-scale aquatic surveys. J. North Am. Benthol. Soc. $27,878-891$.

Tao, T., Stevenson, R.J., Infante, D.M., 2016. Accounting for regional variation in both natural environment and human disturbance to improve performance of multimetric indices of lotic benthic diatoms. Sci. Total Environ. 568, 1124-1134.

USEPA, 2016. National Wetland Condition Assessment 2011: A Collaborative Survey of the Nation's Wetlands.

Vander Laan, J.J., Hawkins, C.P., 2014. Enhancing the performance and interpretation of freshwater biological indices: An application in arid zone streams. Ecol. Indic. 36, 470-482.

Van Sickle, J., Hughes, R.M., 2000. Classification strengths of ecoregions, catchments, and geographic clusters for aquatic vertebrates in Oregon. J. North Am. Benthol. Soc. 19, 370384.

Wang, Y.-K., Stevenson, R.J., Metzmeier, L., 2005. Development and evaluation of a diatom-based Index of Biotic Integrity for the Interior Plateau Ecoregion, USA. J. North Am. Benthol. Soc. 24, 990-1008.

Wang, Y.-K., Stevenson, R.J., Sweets, P.R., DiFranco, J., 2006. Developing and Testing Diatom Indicators for Wetlands in the Casco Bay Watershed, Maine, USA. Hydrobiologia 561, 191206.

Whittier, T.R., Van Sickle, J., 2010. Macroinvertebrate tolerance values and an assemblage tolerance index (ATI) for western USA streams and rivers. J. North Am. Benthol. Soc. 29, 852-866.

Zalack, J.T., Smucker, N.J., Vis, M.L., 2010. Development of a diatom index of biotic integrity for acid mine drainage impacted streams. Ecol. Indic. 10, 287-295.

Zimba, P.V., Hopson, M.S., 1997. Quantification of epiphyte removal efficiency from submersed aquatic plants. Aquat. Bot. 58, 173-179. 